Frontiers of Information Technology \& Electronic Engineering www.jzus.zju.edu.cn; engineering.cae.cn; www.springerlink.com ISSN 2095-9184 (print); ISSN 2095-9230 (online)

E-mail: jzus@zju.edu.cn

\title{
Erratum:
}

\section{Erratum to: A novel method based on convolutional neural networks for deriving standard 12-lead ECG from serial 3-lead ECG}

\author{
Lu-di WANG ${ }^{1}$, Wei ZHOU ${ }^{2}$, Ying XING ${ }^{1}$, Na LIU $^{2}$, \\ Mahmood MOVAHEDIPOUR ${ }^{3,4}$, Xiao-guang ZHOU ${ }^{\dagger * 1}$ \\ ${ }^{1}$ Automation School, Beijing University of Posts and Telecommunications, Beijing 100876, China \\ ${ }^{2}$ Department of Neuroscience, Uppsala University, Uppsala 75105, Sweden \\ ${ }^{3}$ School of Economic and Management, Beijing University of Posts and Telecommunications, Beijing 100876, China \\ ${ }^{4}$ Academic Center for Education, Culture and Research (ACECR), Tehran 14155-4364, Iran \\ †E-mail: zxg_bupt@126.com
}

https://doi.org/10.1631/FITEE.17e 0413

Erratum to: Front Inform Technol Electron Eng, 2019, 20(3):405-413 https://doi.org/10.1631/FITEE.1700413

The financial support information in the original article is incorrect. The correct information is given below:

Project supported by the National Natural Sci- ence Foundation of China (No. 61702044), the Fundamental Research Funds for the Central Universities, China (No. 2017RC27), and the BUPT Excellent Ph.D. Students Foundation.

The online version of the original article can be found at https://doi.org/10.1631/FITEE.1700413

¿ Corresponding author

(b) ORCID: Xiao-guang ZHOU, http://orcid.org/0000-0002-1829-927X

(C) Zhejiang University and Springer-Verlag GmbH Germany, part of Springer Nature 2019 